\title{
Bacterial Pre-Release Testing of Platelets - the Australian Red Cross Blood Service Clinical Experience
}

\author{
Marija Borosak Erica Wood \\ Transfusion Medicine Services, Australian Red Cross Blood Service, South Melbourne, Australia
}

\section{Keywords}

Bacterial testing - Platelets - Septic transfusion reaction

\section{Summary}

The risk of bacterial transmission by platelet transfusion has been recognised internationally as the leading residual infections transfusion risk in the last decade. We describe the clinical and logistical aspects of bacterial contamination screening of platelets introduced in Australia in early 2008. Sampling occurs at $24 \mathrm{~h}$, and platelets are released to hospitals 'negative to date'. Bacterial screening detection of initial machine-positive (IMP) and all follow-up results are notified to transfusing laboratories. Results of screening between 2008 and 2010 found a significant rate of IMP samples $(1.06 \%)$ with a truepositive/indeterminate rate of $0.18 \%$. Components were already transfused in $32.5 \%$ of cases at time of initial notification. Confirmed cases of septic transfusion reactions have declined significantly since the introduction of pre-release platelet screening, reflecting an important additional improvement in transfusion safety in Australia.

\section{Introduction}

The risk of bacterial transmission by platelet transfusion has been recognised internationally as a leading residual risk of transfusion and has gained increased attention over the last

\author{
Schlüsselwörter \\ Bakterielle Testung · Thrombozyten · Septische \\ Transfusionsreaktion
}

\section{Zusammenfassung}

Das Risiko einer bakteriellen Übertragung mittels Thrombozytentransfusion ist international in der zurückliegenden Dekade als das schwerwiegendste noch ungelöste Problem bei Transfusionen erkannt worden. In der vorliegenden Arbeit werden die klinischen und logistischen Aspekte des Anfang 2008 in Australien eingeführten bakteriellen Screenings von Thrombozyten beschrieben. Die Probenentnahme erfolgt innerhalb von $24 \mathrm{~h}$, und die Thrombozyten werden für die Krankenhäuser «negative to date» freigegeben. Der bakterielle Screening-Nachweis von "initial machine-positive» (IMP) und von allen Follow-up-Resultaten wird an die transfundierenden Laboratorien gemeldet. In den Screening-Ergebnissen zwischen 2008 und 2010 fand sich eine signifikante Rate von IMP-Proben mit einer Rate richtig positiv / nicht bestimmbar von $0,18 \%$. In 32,5\% der Fälle waren die Thrombozytenkonzentrate bei der initialen Benachrichtigung bereits transfundiert. Die bestätigten Fälle einer septischen Transfusionsreaktion haben seit der Einführung Thrombozyten-Screenings vor der Freigabe signifikant abgenommen, was eine bedeutende zusätzliche Verbesserung der Transfusionssicherheit in Australien widerspiegelt.

decade. Various complementary measures have been implemented internationally to try to address this hazard [1-3].

Between 2006 and 2007, eight confirmed septic transfusion reactions were reported to the Australian Red Cross Blood Service. Five patients recovered, 1 experienced major morbid-

\begin{tabular}{|c|c|}
\hline KARGER & (c) 2011 S. Karger GmbH, Freiburg \\
\hline $\begin{array}{l}\text { Fax +49 } 7614520714 \\
\text { Information@Karger.de } \\
\text { www.karger.com }\end{array}$ & $\begin{array}{l}\text { Accessible online at: } \\
\text { www.karger.com/tmh }\end{array}$ \\
\hline
\end{tabular}


ity, and 2 patients died. Platelet components were associated with five of the cases, while 3 were related to red cells [4].

The Blood Service donor questionnaire includes questions to assess donor health and to help exclude donors who may have infections or may be at risk of asymptomatic bacteraemia.

Standardised skin cleansing was introduced in late 2004 and diversion of the first $30 \mathrm{ml}$ of whole blood donation in late 2006. These interventions each had a significant impact on contamination rates that were assessed on routine quality control testing and declined over this time, which is in line with experience reported from other centres [5-7].

The licensed/registered routine screening methods all have limitations; however, each incremental step in improving bacterial safety of transfusion is important, and available prevention and detection measures have been introduced in a number of countries, rather than waiting for the 'perfect' solution. This paper describes the clinical and logistical aspects of routine bacterial contamination surveillance screening of platelets in Australia since introduction in early 2008, including implementation, results to date, and some of the successes and lessons learned.

\section{Methods}

Introduction of screening occurred at seven Blood Service testing laboratories (5 new facilities) in late April 2008 using the BacT/ALERT ${ }^{\circledR}$ 3D automated microbial detection system (BioMérieux, Durham, NC, USA).

Closed sampling of 15-20 ml from each platelet component occurs at $24 \mathrm{~h}$, and samples are inoculated for aerobic and anaerobic culture. Platelets are released into Blood Service inventory 'negative to date' while culture continues over the component shelf life. The components are available for issue to hospitals at $24 \mathrm{~h}$ and have a shelf life of 5 days. Components included buffy coat-derived pooled platelets (4 donations) suspended in SSP+ additive (PAS-E) sampled as a pool, and apheresis platelets suspended in plasma (Gambro Trima Accel) sampled individually or pooled if a double collection.

Key implementation issues included:

- set-up of 5 new facilities across a vast nation (seven sites operational initially; Brisbane, Newcastle, Sydney, Melbourne, Hobart, Perth and Townsville),

- immediate remote notification mechanism to flag initial machine-positive (IMP) results and commence the recall of components,

- initiation of urgent Gram stain testing of those components that were already transfused when IMP flagged,

- mechanisms of notification of the clinical treating team.

Communication and education using multiple modalities was undertaken to inform clinicians and hospital laboratory personnel of bacterial screening prior to introduction. In the period following implementation (late April 2008 to end
October 2010) blood service transfusion medicine staff also provided clinical follow-up of cases where transfusion had occurred prior to IMP notification. Transfusing laboratories were provided with initial IMP results where component was transfused, followed by Gram stain, final culture results, and antibiotic sensitivities as soon as these were available.

\section{Results}

Feedback from clinicians generally showed understanding of the rationale to undertake bacterial screening and follow-up. Initial concerns related to management of different clinical scenarios and potential workload for laboratories and clinical staff. Some clinicians were initially apprehensive at first notification and required education about general principles of bacterial contamination and septic transfusion reactions, discussion of the results, and in some cases, assistance with management of individual patients' clinical circumstances.

Over a 3-year period from late April 2008 to end October 2010, 302,386 platelet components were screened. There were 3,207 IMP notifications amounting to a rate of $1.06 \%$, of which $1,041(32.5 \%)$ had related components that were transfused. This translated to 1,060 platelets or their associated components (red cells or plasma).

Of all screened platelets, 550 were confirmed positive/indeterminate $(0.18 \%)$. Confirmed positive is defined as a result where the originally tested platelet concentrate or any associated components has been identified to contain bacteria or where a transfusion recipient has a septic reaction with the same organism being identified in the patient's blood and the transfused component. An indeterminate case is a result where bacteria are identified but the follow-up testing is inconclusive or where the transfused patient shows signs of septic reaction but the cause cannot be identified/confirmed.

In $154(28 \%)$ of these confirmed positive/indeterminate cases the organisms were deemed clinically significant (not Proprionibacterium spp.). Transfusion was prevented in 57\% (88/154) of these cases due to early notification. Although Propionibacterium acnes can be pathogenic in some circumstances, particularly in conjunction with cardiac prosthetic devices [8], generally it is considered to be a skin commensal of minimal clinical importance.

Sole anaerobic yield of significant organisms was $2 \%$ $(64 / 3,207)$, including two confirmed positive cases of Clostridium perfringens where transfusion was prevented. Transfusion occurred in 76\% (300/396) of Proprionibacterium spp. (confirmed/indeterminate), reflecting the mean time to detection of 4.2 days for this organism, compared with the mean time to detection for all non-Proprionibacterium spp. of 2.2 days.

Confirmed cases of septic transfusion reactions have declined significantly since the introduction of bacterial prerelease screening of platelets. There were no cases in 2008, 1 case of probable septic reaction (Pseudomonas putida) in 
2009 associated with a red cell concentrate where no platelet concentrate was manufactured (hence no screening was undertaken on the donation), and 1 case due to coagulase-negative Staphylococcus spp. in 2010. The latter case was one of high clinical probability but not confirmed due to some microbiological ambiguity and lack of molecular confirmation; however, the platelet screening sample showed no growth (possibly false-negative).

The age of platelet inventory was closely monitored at implementation. The major change in platelet issue occurred at day 2 with a higher number of units now being distributed on this day, while the pattern of issue for the remaining self-life remained the same. Considerable planning and careful scheduling of donations (including additional weekend collections and testing) has resulted in adequate levels of inventory even in periods of potential short supply (beginning of the week and public holidays). Careful pre-planning and clinician education was also required in providing HLA-matched and other special platelet support.

\section{Discussion}

A major area of interest following implementation of screening related to patient situations that may require management where platelets had been transfused prior to notification. The Blood Service was not proscriptive in how this should be managed by hospitals and treating clinicians, but encouraged clinical review and management according to the patients' status at the time of transfusion and notification of IMP as well as collection of patient blood cultures and prompt microbiological testing of implicated components wherever possible. Different health services chose to manage patients in different ways. Some arranged for discharged patients to return for assessment immediately, while others did not recall overnight but arranged assessment next morning or immediate assessment by phone. Information leaflets were developed to assist with the education of patients receiving platelet therapy who were ambulatory so that they were aware of the testing, symptoms of bacterial infection, and steps to take if they became unwell or were advised of a bacterial screening-positive result. Some situations necessitated commencement of antibiotics where risk of delay was considered unacceptable, e.g. cardiac or other surgery involving prostheses, and in neutropenic haematology/oncology patients. A Gram stain result from components in house or recalled was made available by the Blood Service as soon as possible to assist with clinical decision making.

Bacterial contamination screening of platelets continues to provide an important improvement in transfusion safety in Australia. A reduction in septic transfusion reactions has occurred, and the transfusion of a number of highly pathogenic organisms could be prevented where contamination had been detected prior to release of product or transfusion. This offsets a substantial workload in detection and notification of Australian health care facilities as well as additional requirements for ongoing clinical support of notifications.

\section{Acknowledgements}

We thank the laboratory and clinical staff of the Australian Red Cross Blood Service for provision of results and other data.

\section{Disclosure Statement}

The authors declared no conflicts of interest.

\section{References}

1 Palavecino EL, Yomtovian RA, Jacobs MR: Bacterial contamination of platelets. Transfus Apher Sci 2010;42:71-82.

2 Wood EM: Prevention of bacterial contamination, including initial flow diversion. ISBT Science Series 2009;4:221-229.

3 Andreu G, Caldani C, Morel P: Reduction of septic transfusion reactions related to bacteria contamination without implementing bacteria detection. ISBT Science Series 2008;3:124-132.
4 Borosak M, Dennington P, Bryant S, Baidya S, Saxon B, Aston L, Wood E, Pink J: Adverse transfusion reaction reporting to the Australian Red Cross Blood Service - 3 years experience, 2006-2008. Blood Transfus 2010;8(suppl 1):s34 (abstract P23).

5 McDonald CP: Bacterial risk reduction by improved donor arm disinfection, diversion and bacterial screening. Transfus Med 2006;16:381-396.

6 de Korte D, Curvers J, de Kort WL, Hoekstra T, van der Poel CL, Beckers EA, Marcelis JH: Effects of skin disinfection method, deviation bag, and bacterial screening on clinical safety of platelet transfusions in the Netherlands. Transfusion 2006; 46:476-485.

\footnotetext{
7 Benjamin RJ, Kline L, Dy BA, Kennedy J, Pisciotto P, Sapatnekar S, Mercado R, Eder AF: Bacterial contamination of whole-blood-derived platelets: the introduction of sample diversion and prestorage pooling with culture testing in the American Red Cross. Transfusion 2008; 48:23482355.

8 Sohail MR, Gray AL, Baddour LM, Tieyjeh IM, Virk A: Infective endocarditis due to Propionibacterium species. Clin Microbiol Infect 2009;15:387394.
} 